\title{
Light-addressable electrochemical sensing with electrodeposited n-silicon/gold nanoparticle Schottky junctions
}

Irina M. Terrero Rodríguez, ${ }^{\dagger}$ Alexandra J. Borrill, ${ }^{\ddagger}$ Katherine J. Schaffer, ${ }^{\dagger}$ Jocelyn B. Hernandez, ${ }^{\dagger}$ and Glen D. O’Neil ${ }^{* *}$

$\dashv$ Department of Chemistry and Biochemistry, Montclair State University, Montclair, NJ 07043, United States

* Department of Chemistry and the Centre for Doctoral Training in Diamond Science and Technology, University of Warwick, Coventry, CV4 7AL, United Kingdom

*To whom correspondence should be addressed: oneilg@montclair.edu

$\underline{\text { Section }}$ Page

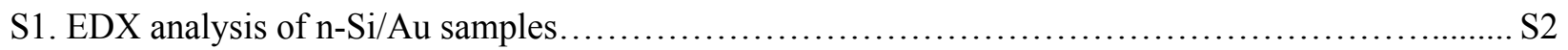

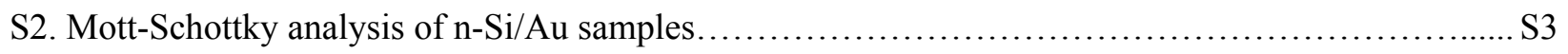

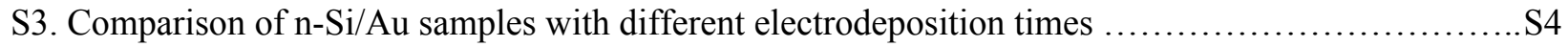

$\mathrm{S} 4$. Additional electrochemical characterization of $\mathrm{n}-\mathrm{Si} / \mathrm{Au}$ samples and control measurements using freshly

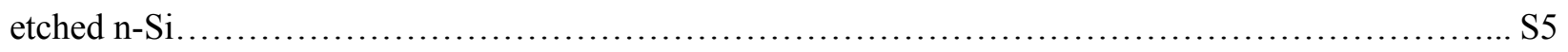

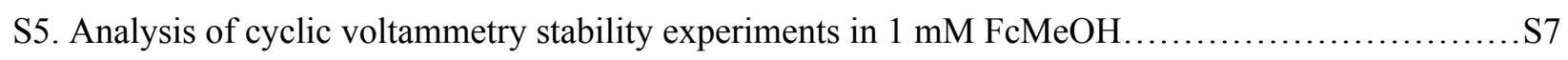

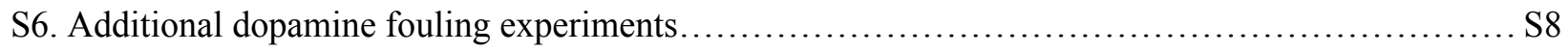

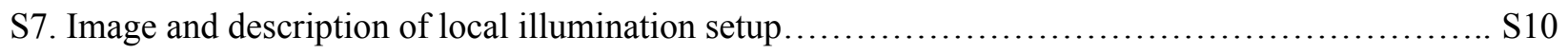

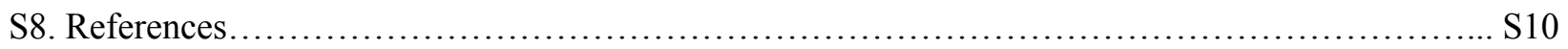




\section{Section S1. EDX analysis of n-Si/Au samples}

The images were obtained using a Hitachi S-3400N SEM in secondary electron mode using a 30-kV accelerator voltage. EDX mapping confirmed that the electrode surface is mostly Au and Si.
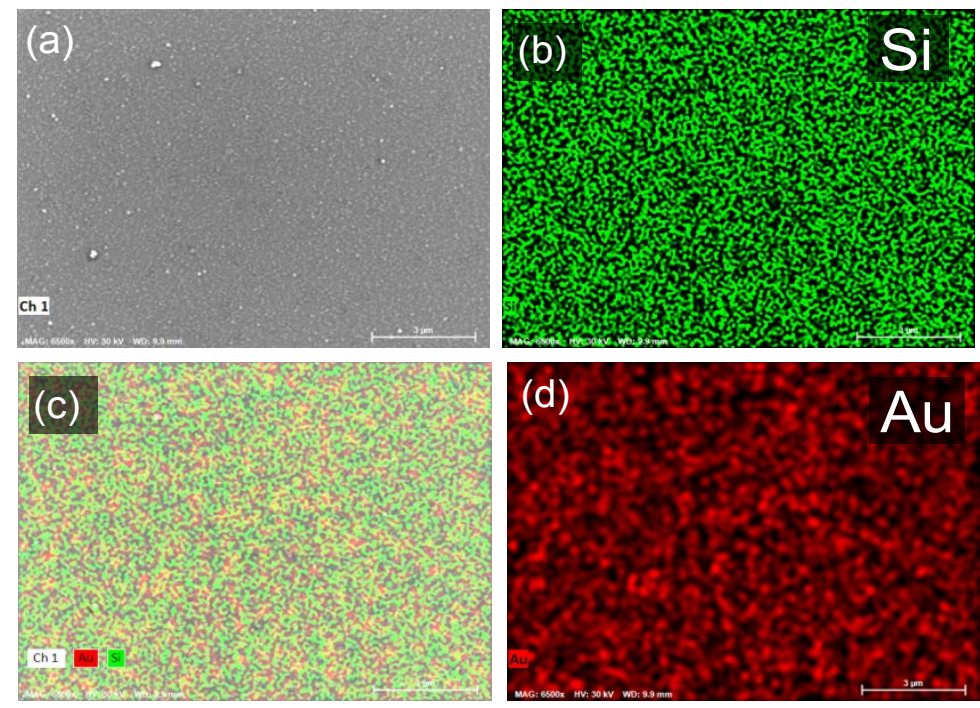

Figure S1: (a), (b), (c) and (d) EDX map of n-Si|Au photoelectrode prepared using a twenty minute electrodeposition time. Scale bars are $3 \mu \mathrm{m}$.

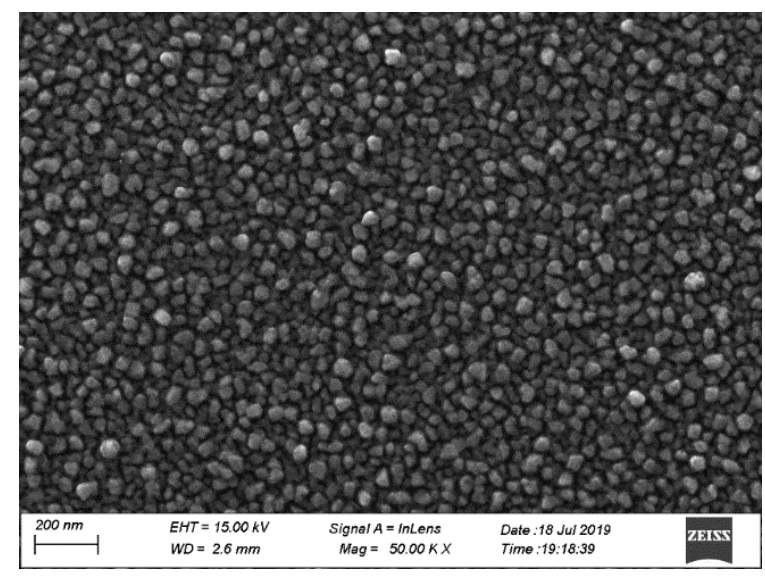

Figure S2: SEM image of n-Si/Au sample prepared with a 20-minute electrodeposition. 


\section{$\underline{\text { Section S2. Mott-Schottky analysis of n-Si/Au samples }}$}
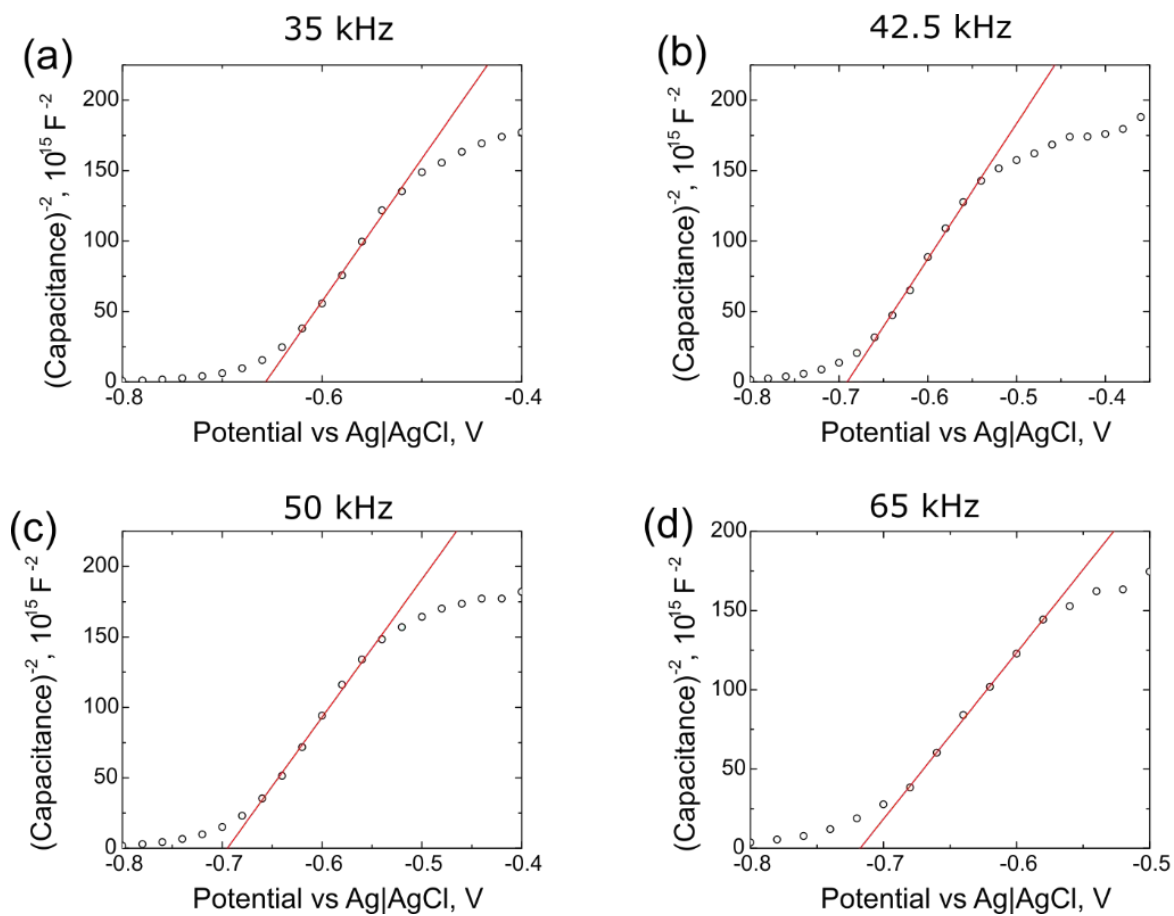

Figure S3: Mott-Schottky plot of n-type Si/Au photoelectrode prepared using a 5-minute electrodeposition time at (a) 35, (b) 42.5 , (c) 50 and (d) $65 \mathrm{kHz}$

Mott-Schottky plots (Fig. S3) were recorded in $1 \mathrm{mM} \mathrm{FcMeOH} / 0.1 \mathrm{M} \mathrm{KCl}$ electrolyte over a -0.8 to $0 \mathrm{~V}$ range with an impedance measurement made every $20 \mathrm{mV}$. We fit the data to the Mott-Schottky equation to find the flat-band potential $\left(E_{\mathrm{fb}}\right)$ and the bulk dopant concentration $\left(N_{\mathrm{d}}\right)$. The Mott-Schottky equation (Equation $\mathrm{S} 1)$ relates the capacitance of the space charge region $\left(C_{\mathrm{SC}}\right)$ to the potential of an electrode versus a reference $(E):{ }^{1}$

$\frac{1}{C_{S C}^{2}}=\frac{2}{q \varepsilon \varepsilon_{0} N_{d} A^{2}}\left(E-E_{f b}-\frac{k_{B} T}{q}\right)$

where $k_{\mathrm{B}}$ is Boltzmann's constant, $\varepsilon$ is the dielectric constant of the semiconductor (11.7 for $\left.\mathrm{Si}\right), \mathrm{A}$ is the electrode area $\left(=0.13 \mathrm{~cm}^{2}\right)$ and $\varepsilon_{0}$ is permittivity of free space. The $\mathrm{x}$-intercept of the linear portion corresponds to $E_{\mathrm{fb}}+k_{\mathrm{B}} T q^{-1}$, while the slope of the line is related to bulk dopant concentration. The average $E_{\mathrm{fb}}$ value was $-0.66 \pm 0.02 \mathrm{~V}$ vs. $\mathrm{Ag} \mid \mathrm{AgCl}$ and the average bulk dopant concentration was $7.6( \pm 0.3) \bullet 10^{14}$ $\mathrm{cm}^{-3}$. 


\section{Section S3. Comparison of n-Si/Au samples prepared with different electrodeposition times}

The impact of $\mathrm{Au}$ electrodeposition time was studied by preparing samples and comparing their behavior using $\mathrm{CV}$ in $1 \mathrm{mM} \mathrm{FcMeOH}$. Fig. $\mathrm{S} 4$ shows four $\mathrm{CVs}$ collected at $0.1 \mathrm{~V} \mathrm{~s}^{-1}$. The minor differences in the peak heights are caused by differences in the electrode area from the masking process (see main text). The peak-potential differences are 66,64, 65, and $61 \mathrm{mV}$ for the 5, 10, 15, and 20 minute samples, respectively. The half-wave potentials are $-0.148,-0.149,-0.141$, and $-0.138 \mathrm{~V}$ vs. $\mathrm{Ag} / \mathrm{AgCl}$ for the 5,10 , 15, and 20 minute samples, respectively. Taken together, this suggests that the Au electrodeposition time does not influence the electrochemical behavior of the sensors.

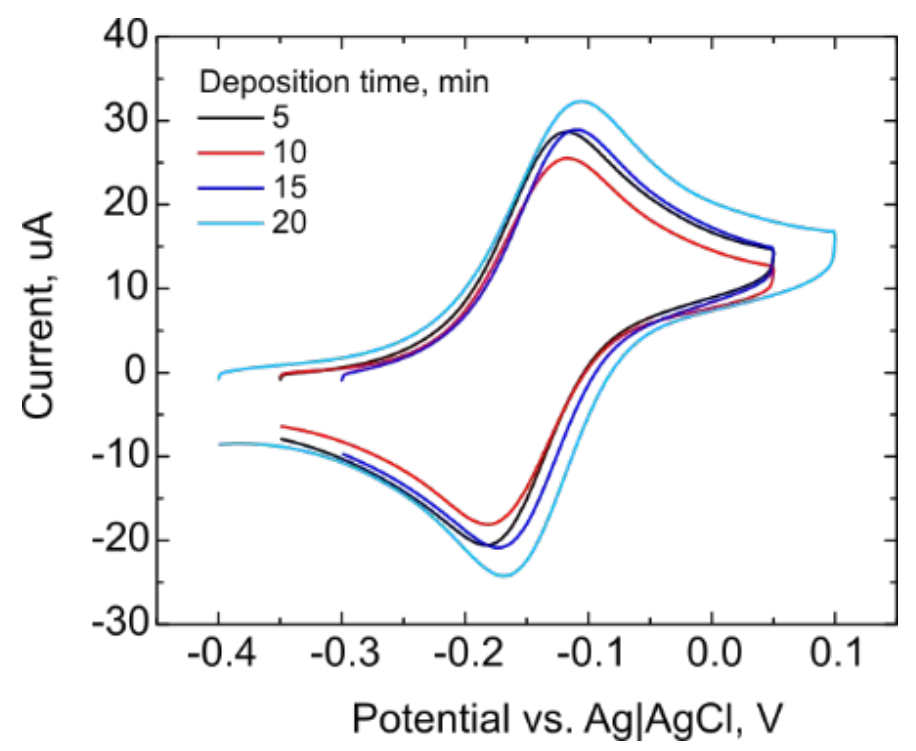

Figure S4: CVs of $1 \mathrm{mM} \mathrm{FcMeOH}$ in $0.1 \mathrm{M} \mathrm{KCl}$ at $100 \mathrm{mV} \mathrm{s}^{-1}$ scan rate using n-Si/Au photo electrodes prepared with 5 (black trace), 10 (red trace), 15 (dark blue) and 20 (light blue) Au deposition times under full illumination. 
Section S4. Additional electrochemical characterization of $\mathrm{n}-\mathrm{Si} / \mathrm{Au}$ samples and control measurements using freshly etched n-Si

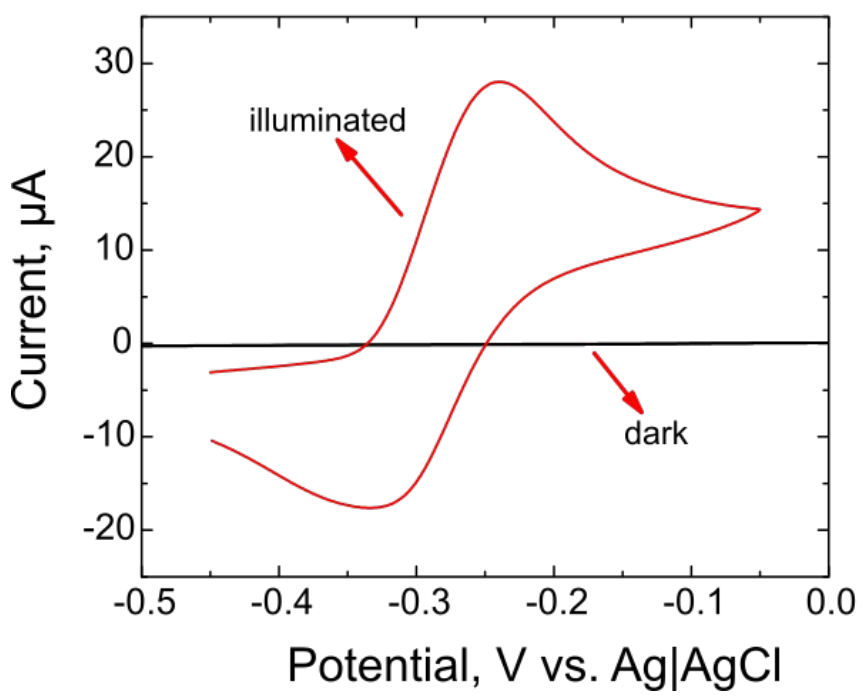

Figure S5: CVs of $1 \mathrm{mM} \mathrm{FcMeOH} / 0.1 \mathrm{KCl}$ using a bare n-type Si photoelectrode in the dark (black trace) and fully illuminated (red trace). Counter $=$ graphite, scan rate $=0.1 \mathrm{~V} \mathrm{~s}^{-1}$

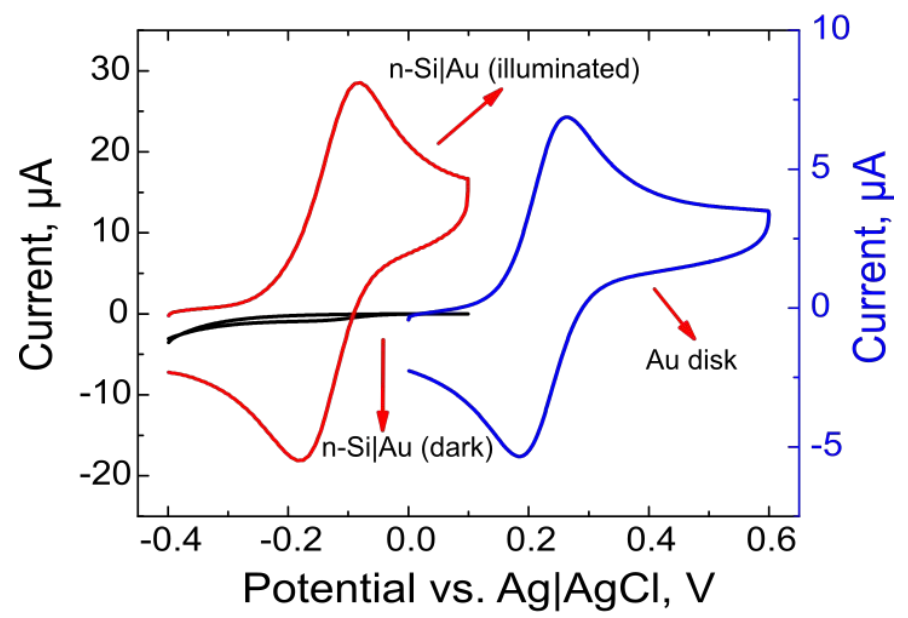

Figure S6: $\mathrm{CVs}$ of $1 \mathrm{mM} \mathrm{Fe}(\mathrm{CN})_{6}{ }^{4-}$ using Au disk electrode in the dark (blue trace), and semiconducting n-type Si/Au photoelectrodes prepared using 5 min electrodeposition in the dark (black trace) and fully illuminated (red trace). 
Fig. S6 shows $\mathrm{CVs}$ of $\mathrm{Fe}(\mathrm{CN})_{6}^{4-}$ in $0.1 \mathrm{M} \mathrm{KCl}$ using n-Si/Au and $\mathrm{Au}$ disk electrodes. The $E^{\mathrm{o}}$ for $\mathrm{Fe}(\mathrm{CN})_{6}{ }^{4-}$ is $\sim 0.25 \mathrm{~V}$ vs. $\mathrm{Ag} / \mathrm{AgCl}$ and it should therefore be light-activated using this sensor because $E^{\mathrm{o}}$ is more positive than $E_{\mathrm{fb}}$. The blue trace in Fig. S5 shows a CV of a metallic Au disk electrode. The black trace shows the $\mathrm{n}-\mathrm{Si} / \mathrm{Au}$ sensor in the dark and the red trace is the $\mathrm{n}-\mathrm{Si} / \mathrm{Au}$ under illumination. Comparison of the red and black traces demonstrate that the LAES is activated by light for the oxidation of $\mathrm{Fe}(\mathrm{CN})_{6}{ }^{4-}$. By comparing the red and blue traces, it is clear that the n-Si/Au sensor behaves nearly identically to the metallic Au disk.
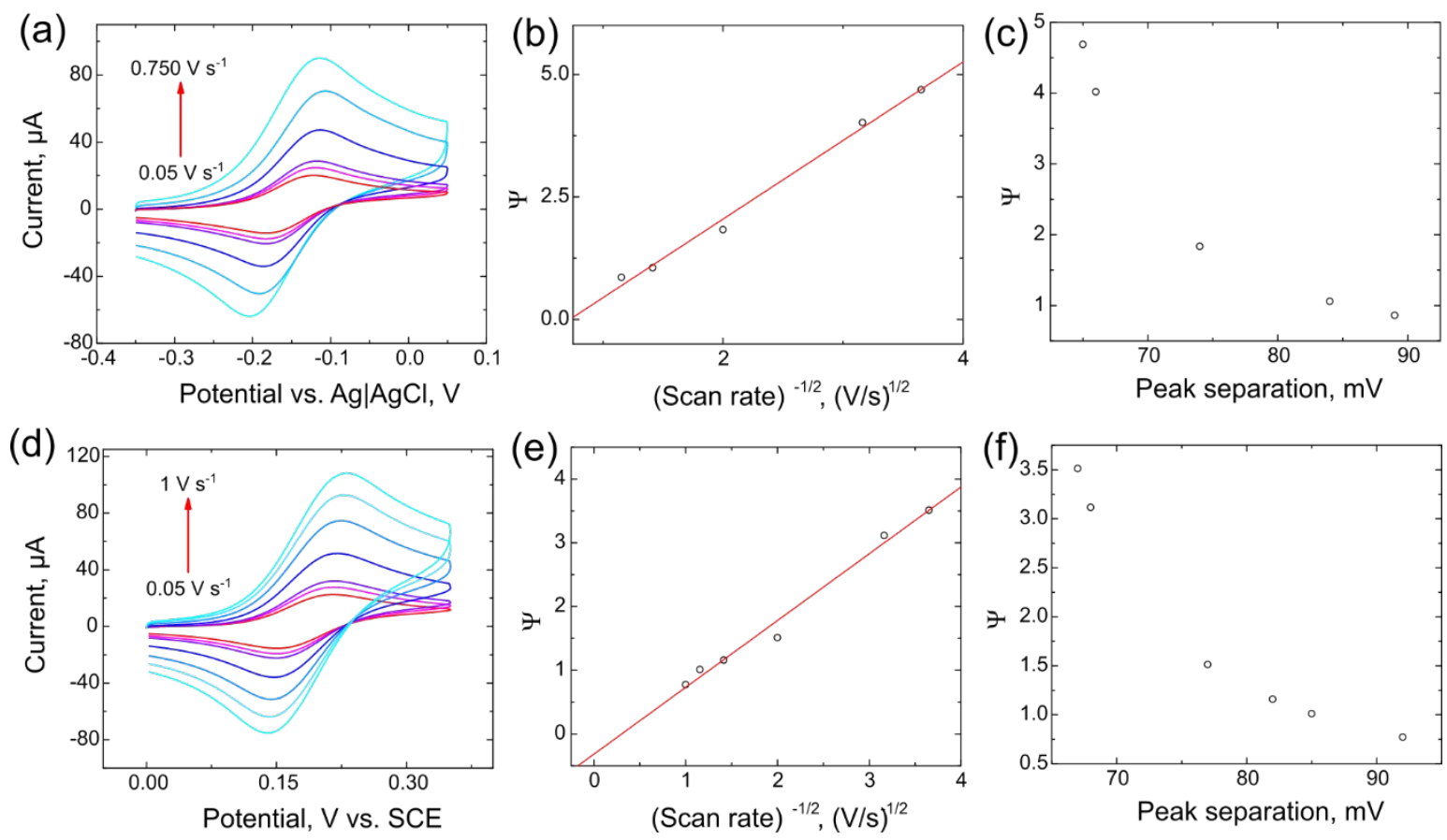

Figure S7: Results of scan rate study for $\mathrm{n}-\mathrm{Si} / \mathrm{Au}\left(\mathrm{a}, \mathrm{b}\right.$, and c) and $\mathrm{p}^{*}-\mathrm{Si} / \mathrm{Au}(\mathrm{d}, \mathrm{e}$, and f) sensors. (a) CVs of FcMeOH using n-Si/Au samples at scan rates from 0.05 to $0.75 \mathrm{~V} \mathrm{~s}^{-1}$; (b) plot of $\psi$ vs. $v^{-1 / 2}$ for determination of $k^{0}$ using the Nicholson method for $\mathrm{n}-\mathrm{Si} / \mathrm{Au}$ sensors; (c) plot of $\psi$ vs. $\Delta E \mathrm{p}$ for $\mathrm{n}-\mathrm{Si} / \mathrm{Au}$ sensors; (d) CVs of FcMeOH using $\mathrm{p}^{*}$-Si/Au samples at scan rates from 0.05 to $1 \mathrm{~V} \mathrm{~s}^{-1}$; (b) plot of $\psi$ vs. $v^{-}$ ${ }^{1 / 2}$ for determination of $k^{0}$ using the Nicholson method for $\mathrm{p}^{*}$-Si/Au sensors; (c) plot of $\psi$ vs. $\Delta E \mathrm{p}$ for $\mathrm{p}^{*}$ $\mathrm{Si} / \mathrm{Au}$ sensors. 


\section{Section S5. Analysis of cyclic voltammetry stability experiments in $1 \mathrm{mM} \mathrm{FcMeOH}$}
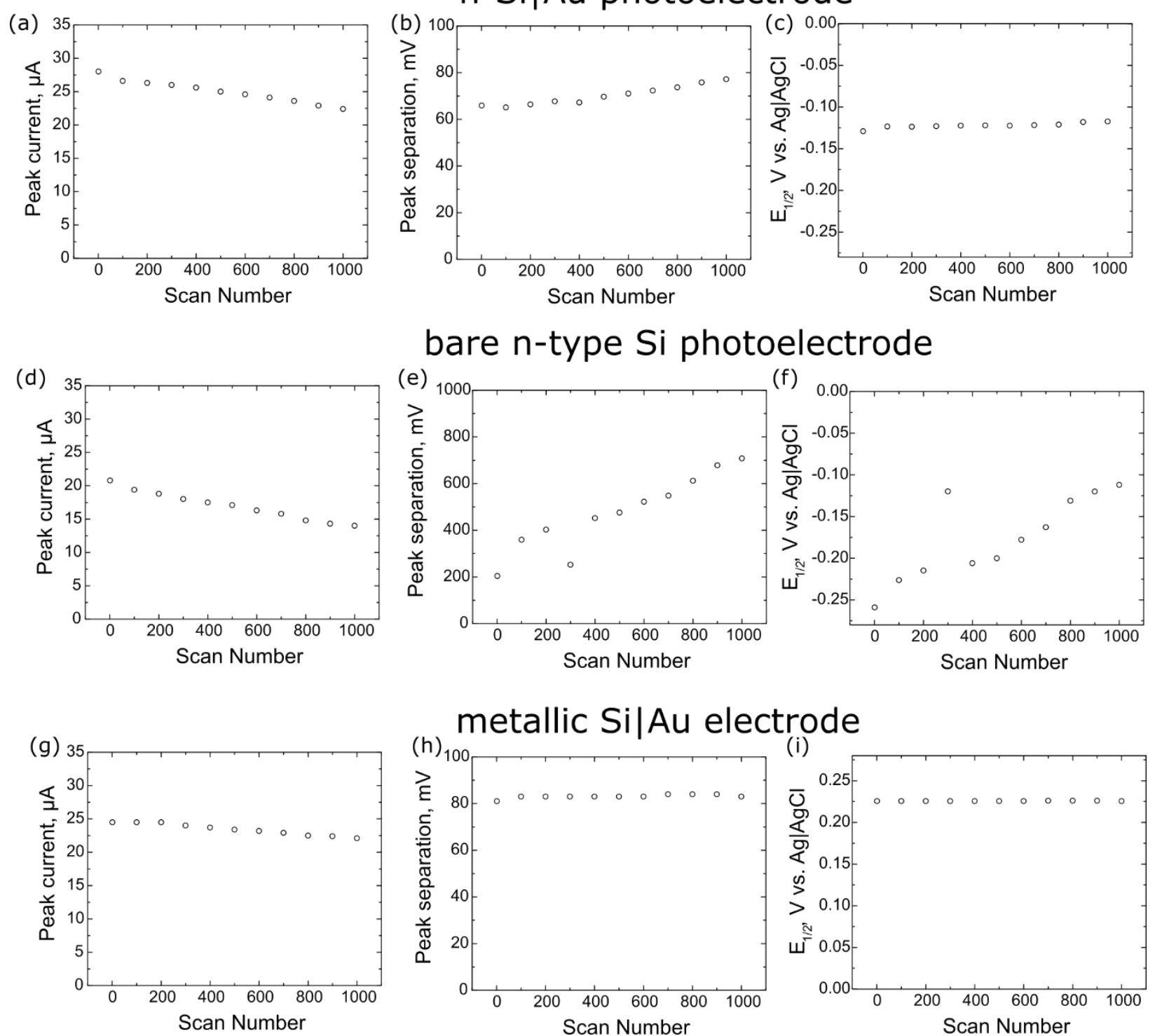

Figure S8: Plots of anodic peak current as a function of scan number (a,d,g), peak separation as a function of scan number (b,e,h) and $E_{1 / 2}$ as a function of scan number (c,f,i). Peak current, peak separation and $E_{1 / 2}$ values were obtained from 1000 continuous CVs collected in $1 \mathrm{mM} \mathrm{FcMeOH}, 0.1 \mathrm{M}$ $\mathrm{KCl}$ under illumination using either an $\mathrm{n}-\mathrm{Si} / \mathrm{Au}$ photoelectrode prepared using 5 minute electrodeposition time (a,b, and c), a bare n-type Si photoelectrode (d,e,f) or a highly doped p* Si|Au electrode (g,h,i). For all $\mathrm{CVs}$, scan rate $=0.1 \mathrm{~V} \mathrm{~s}^{-1}$, reference electrode $=\mathrm{Ag} / \mathrm{AgCl}$, counter electrode $=$ graphite rod. 


\section{Section S6. Additional dopamine fouling experiments.}

Dopamine oxidation still occurs without the presence of Au NPs when the sample is illuminated. However, Au NPs improve the kinetics of the reaction, as evidenced by the presence of a cathodic peak when the CVs are collected using an n-type Si photoelectrode protected with Au NPs (Fig 4).

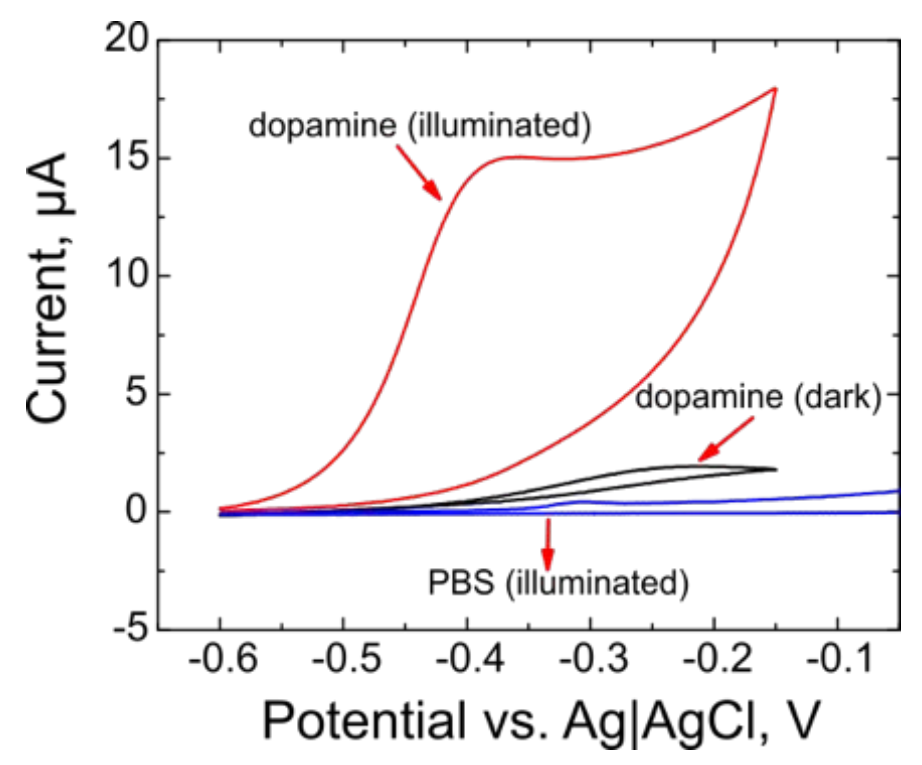

Figure S9: CVs of $1 \mathrm{mM}$ dopamine in $\mathrm{pH} 8 \mathrm{PBS}$ using a bare n-type Si photoelectrode in the dark (black trace), fully illuminated (red trace) and CV of fully illuminated PBS (blue trace). Scan rate $0.1 \mathrm{~V} \mathrm{~s}^{-1}$.

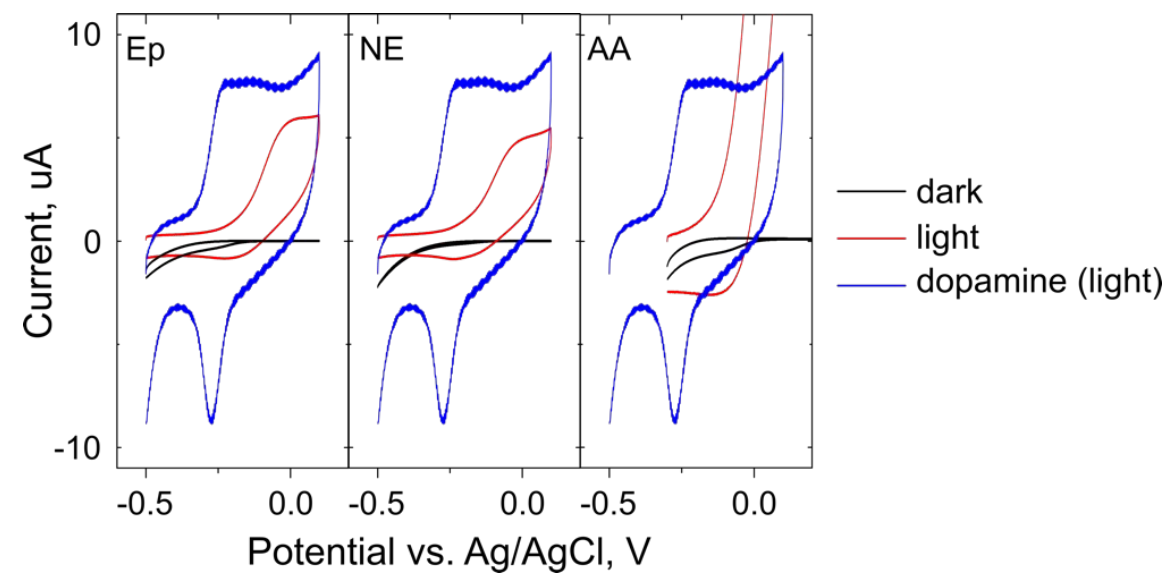

Figure S10: CVs of (a) $50 \mu \mathrm{M}$ epinephrine, (b) $50 \mu \mathrm{M}$ norepinephrine, and (c) $10 \mathrm{mM}$ ascorbic acid in pH 7.4 PBS using a 5-minute n-Si/Au sample. Scan rate $0.25 \mathrm{~V} \mathrm{~s}^{-1}$. A CV of $33 \mu \mathrm{M}$ dopamine (blue trace) is included for comparison. 


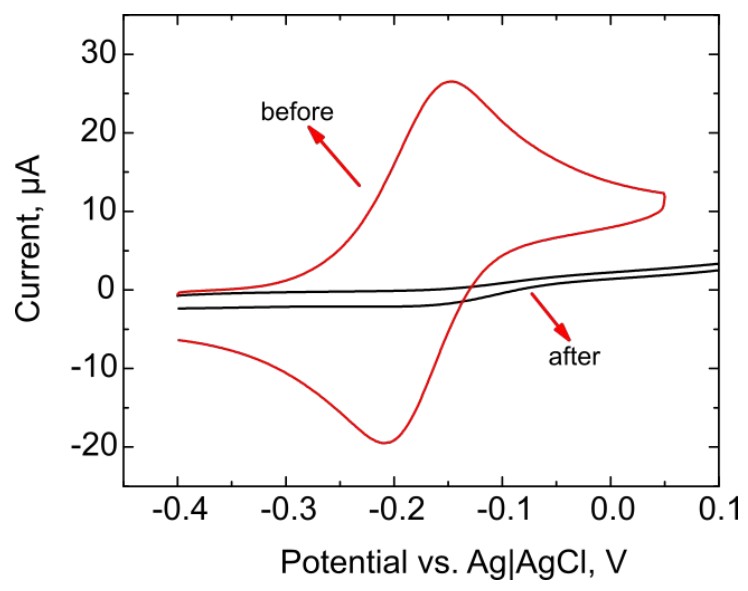

Figure S11: CVs of $\mathrm{FcMeOH}$ taken with n-type $\mathrm{Si} / \mathrm{Au}$ photoelectrode before and after dopamine fouling experiments highlighting that the formation of poly(dopamine) blocks the surface towards electron transfer.
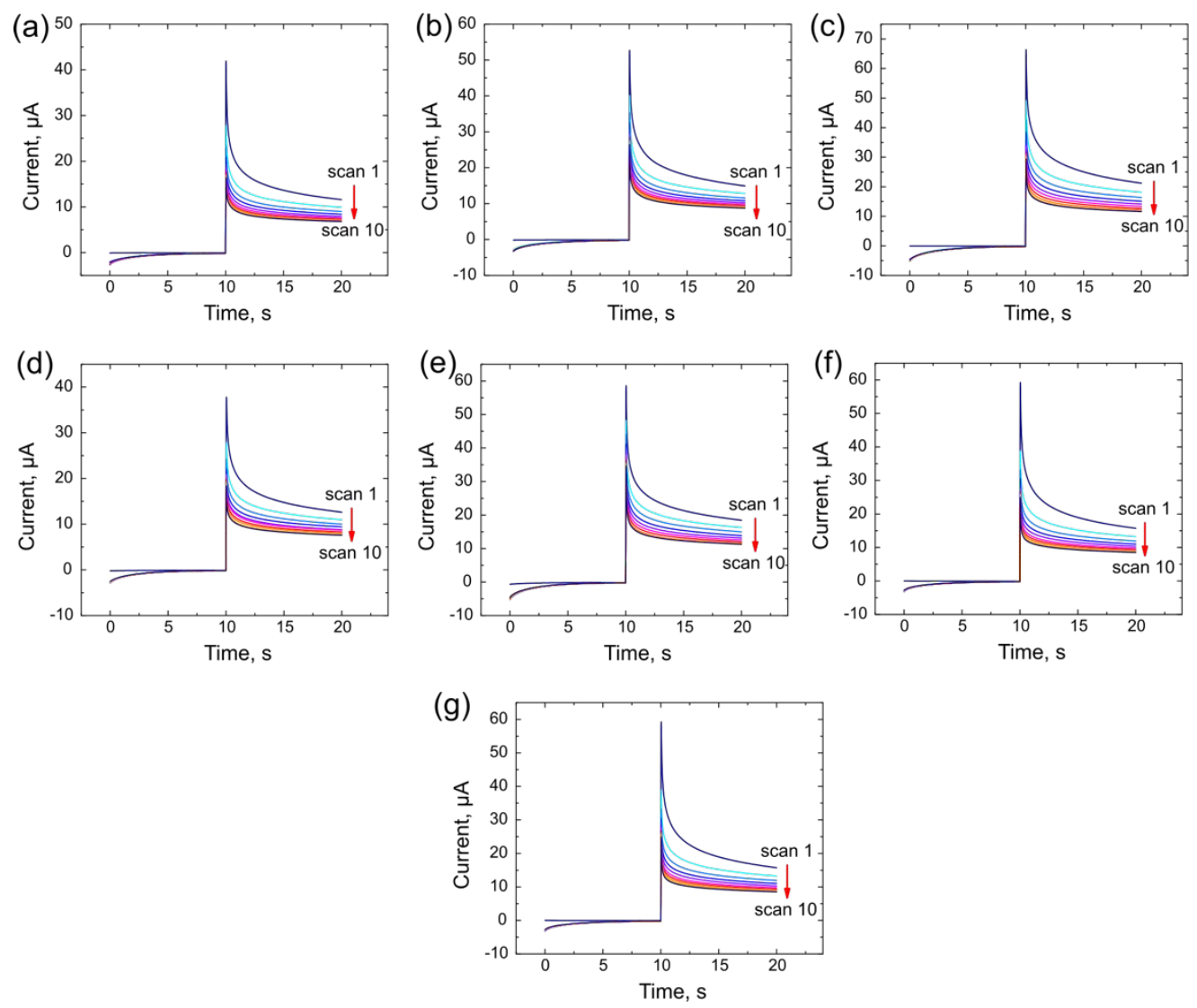

Figure S12: Chronoamperometric $i-t$ traces of seven different locations of a n-Si/Au sensor used for Fig. $5 \mathrm{c}$ in the main text. 


\section{Section S7. Image and description of local illumination setup}

Fig. S13 shows a photo of the setup used for local illumination experiments. Our HEKA ElProScan scanning electrochemical workstation was modified to include a moveable light source. We use a $500 \mu \mathrm{m}$ diameter optical fiber to deliver light from an LED source (530 nm; Thorlabs M530F2), which is collimated (Thorlabs F240SMA-532) and focused onto a 10X microscope objective (NA = 0.24, AM Scope). The entire optical assembly is mounted on a custom 3D printed housing and bolted to a programmable $\mathrm{Z}$ stage. The light beam is focused on the sample by changing the $\mathrm{Z}$ position of the motorized $\mathrm{Z}$ stage. The position of the light beam on the sample can be manipulated by scanning the sample using the programmable XY stage.

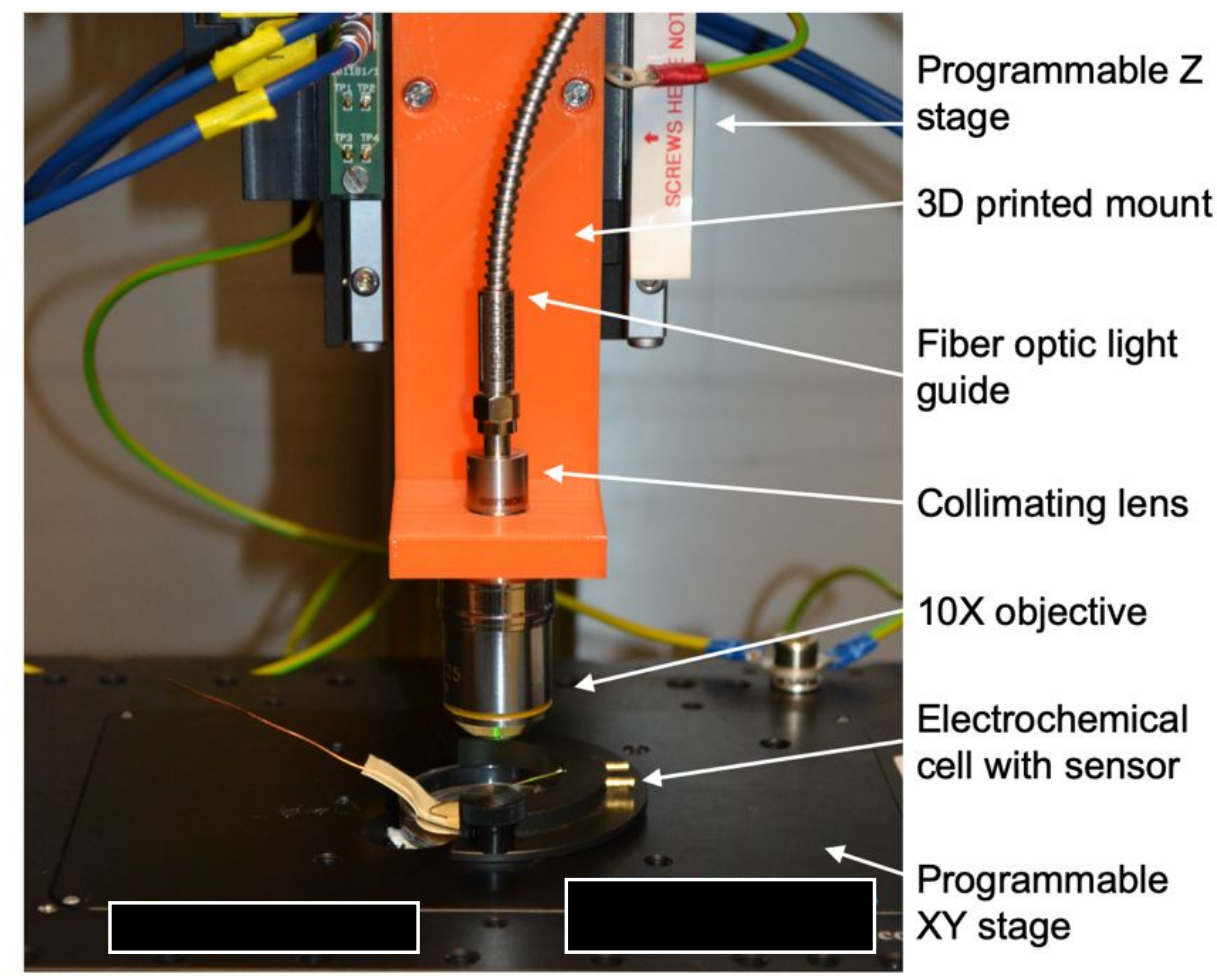

Figure S13: Modified HEKA ElProScan scanning electrochemical workstation used for local illumination experiments. Note the black boxes were added to obscure the company logo as per ACS Copyright guidelines.

\section{Section S8: References}

(1) Acharya, S.; Lancaster, M.; Maldonado, S. Semiconductor Ultramicroelectrodes: Platforms for Studying Charge-Transfer Processes at Semiconductor/Liquid Interfaces. Anal. Chem. 2018, 90, 
12261-12269. 